\title{
The Development of Blended Learning through Learning by Teaching for Mathematical Literacy in General Education Program on Higher Education
}

\author{
Pakwan Riyapan $^{1, *}$, Areena Hazanee ${ }^{1}$, Tatdow Pansombut ${ }^{1}$, Jirapond Muangprathub ${ }^{2}$, Arthit Intarasit ${ }^{1}$ \\ ${ }^{1}$ Faculty of Science and Technology, Prince of Songkla University, Pattani Campus, Pattani, Thailand \\ ${ }^{2}$ Faculty of Science and Industrial Technology, Prince of Songkla University, Suratthani Campus, Suratthani, Thailand
}

Received March 31, 2020; Revised February 18, 2021; Accepted February 26, 2021

Cite This Paper in the following Citation Styles

(a): [1] Pakwan Riyapan, Areena Hazanee, Tatdow Pansombut, Jirapond Muangprathub, Arthit Intarasit, "The Development of Blended Learning through Learning by Teaching for Mathematical Literacy in General Education Program on Higher Education," Universal Journal of Educational Research, Vol. 9, No. 3, pp. 556-563, 2021. DOI: 10.13189/ujer.2021.090315.

(b): Pakwan Riyapan, Areena Hazanee, Tatdow Pansombut, Jirapond Muangprathub, Arthit Intarasit (2021). The Development of Blended Learning through Learning by Teaching for Mathematical Literacy in General Education Program on Higher Education. Universal Journal of Educational Research, 9(3), 556-563. DOI: 10.13189/ujer.2021.090315.

Copyright $\mathrm{C} 2021$ by authors, all rights reserved. Authors agree that this article remains permanently open access under the terms of the Creative Commons Attribution License 4.0 International License

\begin{abstract}
Blended learning is a kind of classroom learning which is suitable to help students for promoting their learning with the 21 st century skills. When the collaborative learning is integrated into classroom techniques, blended learning is a way for students to learn their basic knowledge with online technology before they come to classroom, and spend most of their time in the classroom performing team activities to solve new or complex problems. This study proposes a model for teaching and learning in order to develop the blended learning through learning by teaching. Based on the gradual release of responsibility model, rainbow talk is used to encourage students to take responsibility for collaborative learning combined with flipped learning which students are assigned to study lessons and take tests before they come to classroom. This aims at studying effectiveness of the proposed model in order to improve mathematical achievement in mathematical courses of general education program for higher education. The study is a practical research that provides statistical analysis of mathematical learning results of students from the proposed learning model. The results of this study indicate that mathematical achievement of students is attained in accordance with the learning outcomes of the course at a satisfactory level and is satisfied with the learning and teaching at a good level.
\end{abstract}

Keywords Ability for Solving Mathematical Problems, Blended Learning, Learning by Teaching, Mathematical Achievement

\section{Introduction}

\subsection{Theoretical and Conceptual Foundation}

A learning method which students can spend time outside of classroom in learning lessons on their own and applying their knowledge learned outside the classroom is called "flipped classroom" [1]. Flipped (or inverted) learning occurs when students are assigned to learn a lesson before they come to classroom. The lesson may be in the form of a video clip or multimedia learning. The learning time for flipped learning is organized appropriately between teacher-centered and learning-centered activities. Teacher-centered activities such as interactive lecture to review lessons, prepare basic knowledge for students, and student-centered activities such as cooperative learning in the classroom for team-based problem solving with teachers as mentors 
$[2,3]$.

Blended learning is a combination of traditional classroom teaching and online learning that uses online technology to enhance teaching efficiency. This is able to fill regular classrooms to have the most beneficial impact on student learning. In addition, online technology can be flexible in terms of time and place. The flipped learning is blended learning which may also be known as reversed instruction or inverted classroom $[4,5]$.

Blended learning mixed with flipped learning contributes to the learning efficiency of learners. For example, Chen et al. [4] studied a learning plan combining self-regulated strategies with flipped learning which suggests that student self-regulation has been developed, including their strategies of planning, using study time and their learning achievements. The research of $\mathrm{Ng}$ [5] was studied pedagogy using flipped classroom with self-regulation principles for enhancing formative learning outcomes.

Gradual release of responsibility is a model in which the role of the learner is released gradually with the goal of being responsible. The role of the instructor will be reduced by the release of the students until the instructor is only a supporter of their learning. The learning activities of this model allow the group of friends in the class to help each other. Finally, the students must learn by themselves $[6,7]$.

\subsection{Background of the Study}

Mathematical literacy is necessary for the current lifestyle without emphasizing the knowledge of mathematical content that is taught in school or university courses only, but this is taken into account the study of Mathematics in real situations for a variety of contexts.

Smart Math Smart Life course with code 746-102 was a compulsory course for all 1st year students, Prince of Songkla University, Pattani campus, Pattani province, Thailand. This course was in the general course education program in year 2019, aimed to encourage students to have critical thinking and logic in Mathematics.

In this course, mathematical problem solving was used to manage student's learning, so that they could solve mathematical problems according to their academic achievements. This is an important part of mathematical literacy.

This course has been designed according to the principles of outcome-based education (OBE) that sets up a level of learning, so that the students can apply Mathematics to solve their daily problems, including the following four topics (i). Smart computing: rule of three, rules of significant number and numerical rounding, (ii) Smart shopping: percentage, discount, discount percentage, calculator on market payouts and card membership privileges, (iii) Smart healthy: BMI calculation, heart rate zone, cadence rate and power calories of each day and (iv) Smart business: profit and loss, breakeven point and breakeven price.

The feedbacks of students who enrolled this course in the previous semester are useful to take the real situations as the problems in classroom. Moreover, students can apply this in daily life. Mathematical questions in class can help them to promote and motivate them for solving the problem. This reveals all information to make the decision for solving the problem well.

Before the course has been updated, in the 2018 academic year, this course used the teaching and learning model through cooperative learning to apply classroom activities. For classroom activities, students were divided into small groups consisting of 6 members per team to solve their daily problems based on course learning outcomes (CLOs). After the students participated in class, they were able to review the lessons from online tests according to the principles of flipped learning.

According to the previous details, this shows that results of the Pearson correlation give a significant and moderate positive association between students' cooperative learning activities and student's mathematical problem solving ability in real-life situations with the specific (Pearson's $\mathrm{r}(45)=.48, \mathrm{p}<.001)$. Also students' mathematical problem solving ability and student's flipped learning are found by moderately positive correlation (Pearson's $\mathrm{r}(45)=.44, \mathrm{p}$ $<.001)$. The ability of students' mathematical problem is the main capability in this course to solve problems in real-life situations with the specified course learning outcomes.

However, there are some feedbacks from students indicating that outstanding members in the group can be the leader to do the most of work on team activities. This gives rise to other members that cannot participate on the team activities. Therefore, students can get less benefit from learning with this situation. This feedback also satisfies with some researches of Shea [8], Robert and McInnerney [9], and Liu, Joy and Griffiths [10].

Here, our team researchers are interested in the study and development of the teaching and learning model in the form of blended learning to develop students for this course in order to achieve grade-level courses and the 21 st century skills according to the purpose of general education. It also encourages students to have basic Mathematics as a tool for lifelong learning.

The teaching and learning model proposed in this research is the blended-learning model integrated between cooperative learning and flipped learning by using a rainbow talk activity for student's learning achievement.

Rainbow talk activity is learning by teaching that students can prepare their contents freely, including the way to design and create a summary to present their contents or solutions.

Moreover, the blended-learning model integrated between cooperative learning and flipped learning, using the rainbow talk activity conforms by the development of the $21^{\text {st }}$ century skill which is able to take real practice in 
the future career of students [11]. In addition, the rainbow talk activity is a classroom activity that encourages students to solve problems in class, and enhances their responsibility of the duties corresponding to the gradual release of responsibility model (GRRIM).

Some researches indicated that the integration of the GRRIM model with the other learning model is better than the learning model without the GRRIM model [12]).

Therefore, to enhance student's learning achievement, the researchers conduct a classroom action to develop the model of blended learning that integrates cooperative learning and flipped learning incorporating with learning by teaching via rainbow talk activities for the course of Smart Math Smart Life. Furthermore, the effectiveness and satisfaction of the proposed model are also reported.

\subsection{The Purposes of the Study}

The purposes of this study are follows:

1) To develop and study the blended learning model, combining cooperative learning and flipped learning via the rainbow talk activities in order to improve student's learning performance in mathematical literacy.

2) To test the performance of blended-learning models integrated between the cooperative learning and flipped learning by using the rainbow talk activities.

\section{Research Methodology}

This section consists of three subsections as follows:

\subsection{Population and Sample}

1) The population is the 1 st year students, semester 1 , academic year 2019, Prince of Songkla University, Pattani campus, Thailand.

2) The sample group is the 1 st year students, semester 1 , academic year 2019, 57 students who enrolled in the course of Smart Math Smart Life.

\subsection{Research Design}

The classroom action research was conducted to develop the blended learning model, combining cooperative learning and flipped learning, using rainbow talk activities, in order to improve student's learning performance in mathematical literacy. The framework of learning and teaching for research study is illustrated in Fig. 1.

Teaching and learning framework of Smart Math for Smart life 746-102

Academics Year 1/62

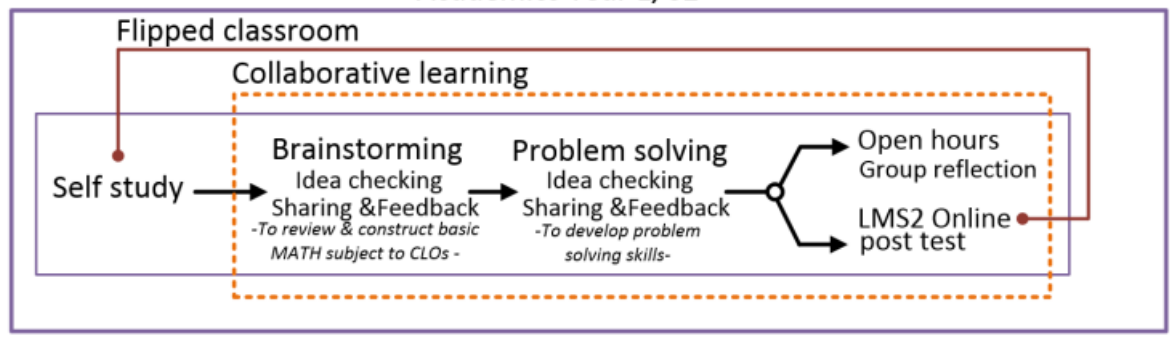

Figure 1. Framework of learning and teaching for course of Smart Math Smart Life Academic Year 2019 
Learning and teaching in classroom according to the learning framework is shown in Figure 1. It includes two stages to improve mathematical literacy. The details of each step are as follows:

\section{Phase 1 Brainstorming, idea checking, sharing and feedback}

Step 1.1 (Week 1) Mathematical knowledge and skills are applied for developing course learning outcomes (CLOs) as follows:

1) Students are assigned to study and read the lessons by themselves via classroom online, then they have to do the test, known as pass ticket, in order to check their understanding of lessons.

2) Students are grouped to brainstorm their ideas with members for creating a chart per group to summarize the content that they are assigned to study.

3) Each student in the group prepares his/her presentation by using the chart from the previous step.

Step 1.2 (Week 2) Review content and check students' understanding by the instructor.

1) Each group is advised to adjust the chart by the instructor according to the criteria for evaluating.

2) Each group is assigned to update the chart according to the instructor's suggestions.

3) Each group prepares the updated chart for next week evaluation.

Step 1.3 (Week 3) Evaluate the learning results from the chart.

1) Each member in the group proposes their topic on the updated chart to the instructor.

2) Each student records a personal video clip based on the topic assigned by the group with the adjusted chart from the previous step. Each group hands in one video clip including all members.

Phase 2 Problem solving, idea checking, sharing and feedback

Step 2.1 Brainstorm.

1) Students are assigned to study the lessons and create the chart.

2) Students are tasked to do a test known as pass ticket in the week before, and they are given a pass ticket for week after before the class ends.

Pass ticket is a pre-test which complies with the CLO to develop.

Step 2.2 Solve problems in everyday life.

1) Students solve the problems assigned about 50 minutes with their group ( 6 members). All problems are satisfied the CLOs by using mathematical knowledge to find the answers.
2) During the group activity or after 25 to 30 minutes that the class begins, the instructor takes idea checking by asking questions from details of the chart of each group and suggests more information that each group needs to update the chart.

3) After the group activity (about 45 minutes), the students are taken the rainbow talk activity by forming new group in order to share and explain solutions to other students in the new group.

4) Before 20 minutes that the class ends, the students are evaluated and given some feedbacks via the rainbow talk activity with other students in the new group.

Step 2.3 Check students' understanding of the problem in activities.

1) Students are provided their solutions in activities to share other students in the classroom via open hours. The instructor always gives some advices and verifies their solutions including summary of some contents.

2) Students are assigned to take online tests via Learning Management System 2 (LMS2) activity.

In order to develop student's mathematical literacy in the classroom, the course learning outcomes based on outcome-based education (OBE) are defined by including the following topics: 1) smart computing, 2) smart healthy, 3) smart shopping and 4) smart business.

The development of student's mathematical literature in the classroom with problem-solving learning is managed as follows: all students are applied by using the phase 1 in the first three weeks (before the midterm and final exams). This phase prepares students for basic knowledge and provides their ideas. Phase 2 occurs in phase 1, including before and after the metaphase. Two topics before the midterm exam are smart computing and smart healthy. After midterm exam, the remaining topics are applied. There are 30 hours of learning in classroom for this semester. So students have to attend in class for 2 hours per week (15 weeks).

\subsection{Data Evaluation}

The evaluation of students' mathematical literacy is taken by using the short answers to evaluate, assessing comprehension of learning outcomes achievements in this course organized for 2 times: midterm and final exams. To do this, the instructor designs 15 questions with short answers according to CLOs for each exam.

Students are taken the flipped classroom via pass ticket as pre-test and online quizzes as post-test for each topic. Classroom activities uses short answers similar manner to assess student's mathematical literacy. In addition, their homework, short video clip presentation, and Info graphic chart with the details are shown in Table 1. 
in General Education Program on Higher Education

Table 1. Assignments and Examinations

\begin{tabular}{|c|c|c|c|}
\hline Assignments/Examinations & Frequency & Classroom & $\%$ of grade \\
\hline $\begin{array}{l}\text { Pass tickets: } 8 \text { Pre-tests covered by the specific content before } \\
\text { class begins, assessing basic comprehension of concepts to } \\
\text { develop CLOs }\end{array}$ & $\begin{array}{l}\text { One per section, roughly one per } \\
\text { week }\end{array}$ & Traditional & 10 \\
\hline $\begin{array}{l}\text { Homework: } 2 \text { assignments, solve real-world problems in daily } \\
\text { life subjected to integrate CLOs }\end{array}$ & 2 & Flipped & 5 \\
\hline $\begin{array}{l}\text { Online quizzes: } 5 \text { quizzes, multiple choices subjected to } \\
\text { integrate CLOs }\end{array}$ & $\begin{array}{l}\text { One per section, roughly one for } 1.5 \\
\text { to } 2 \text { weeks }\end{array}$ & Traditional & 10 \\
\hline $\begin{array}{l}\text { Problem solving in class activities: short answer, assessing } \\
\text { achievement of course learning outcomes }\end{array}$ & $\begin{array}{c}\text { During each class meeting about } 5 \\
\text { activities }\end{array}$ & Traditional & 15 \\
\hline $\begin{array}{l}\text { Short video clip presentation: } 2 \text { of individual short video clips } \\
\text { to present ideas and concepts from CLOs and } 2 \text { of individual } \\
\text { short video clips in rainbow talk activity to present answering } \\
\text { ideas of problem solving in class }\end{array}$ & 4 & Traditional & 20 \\
\hline $\begin{array}{l}\text { Info graphic chart: summary of basic concepts explored in } \\
\text { brainstorming session in class }\end{array}$ & 2 & Traditional & 10 \\
\hline $\begin{array}{l}\text { Exams: short answers, assessing comprehension of learning } \\
\text { outcomes achievements in this course }\end{array}$ & $\begin{array}{l}\text { Two exams per semester, midterm } \\
\text { and final exams }\end{array}$ & Traditional & 30 \\
\hline
\end{tabular}

Table 2. Student's characteristics

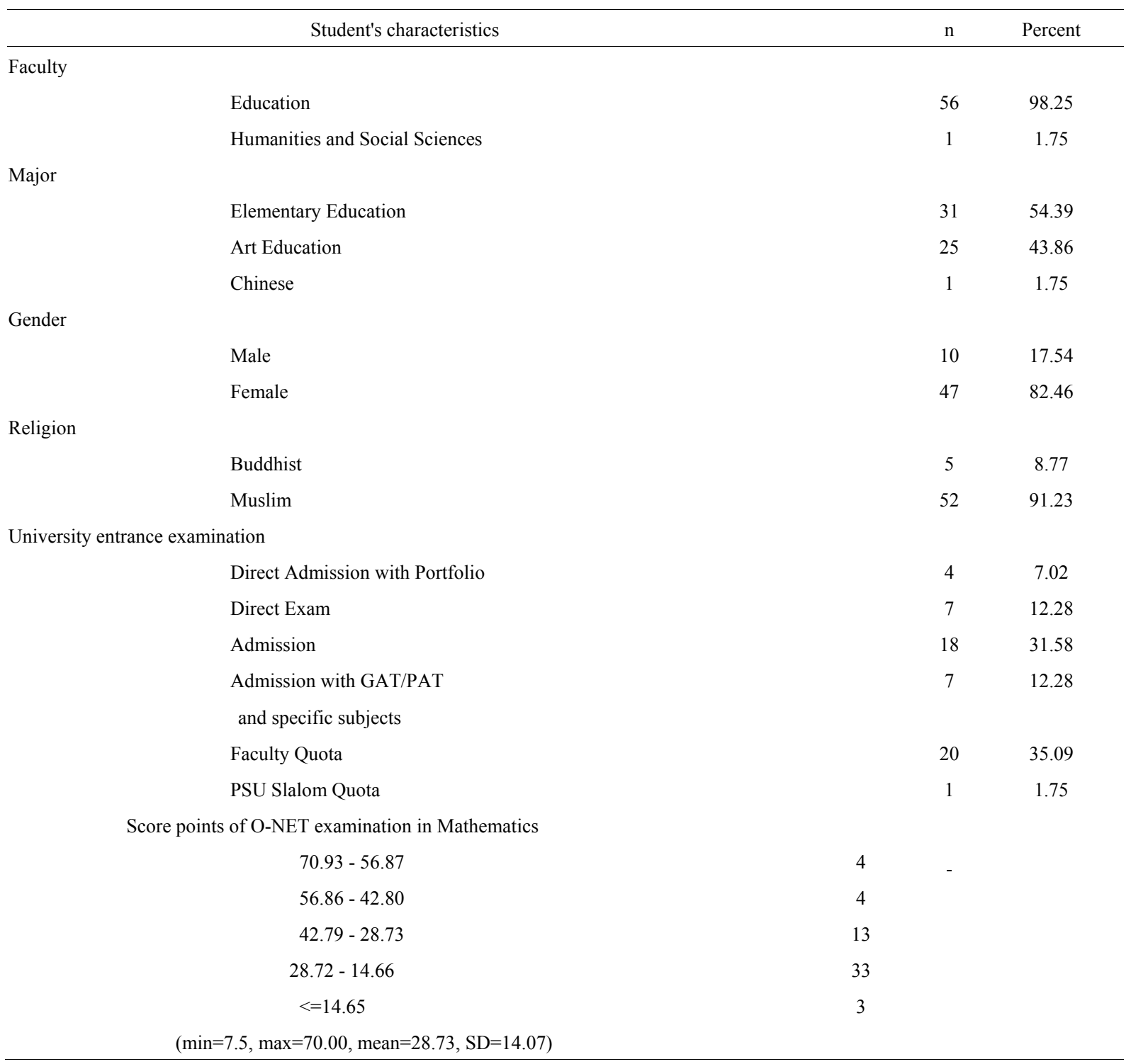




\section{Research Results}

\subsection{Preliminary Results}

The samples consist of $571^{\text {st }}$ year students who were enrolled in the course of Smart Math Smart life, code 746-102 in academic year 2019. They studied in the Faculty of Education with $98.25 \%$, major Elementary Education $(n=31)$ and Art Education $(n=25)$. There was a remaining student from the Faculty of Humanities and Social Sciences, major in Chinese $(\mathrm{n}=1)$ as shown in Table 2. In addition, Table1 also shows that the most of the gender is female ( $\mathrm{n}=47,82.46 \%)$ and most of the religion is Muslim ( $\mathrm{n}=52,91.23 \%)$, and the majority of them had score points in the Ordinary National Educational Test (O-Net) from $14.66 \%$ to $28.72 \%$ _(Mean $=28.73, \mathrm{SD}=14.07$ ). However, the average score of Mathematics in the O-Net for these students is $30.72 \%$ ( $S D=20.49$ ).

\subsection{Statistical Analysis Their Data}

A paired-sample t-test indicates that the post-test scores $(\mathrm{M}=26.4, \mathrm{SD}=7.41)$ are significantly higher than the pre-test scores $(\mathrm{M}=18.0, \mathrm{SD}=9.49), \mathrm{t}(721)=23.3$, $\mathrm{p}$ $<.001, \mathrm{~d}=0.87$. Thus, this implies that the proposed learning model results in a significant improvement in student's Mathematics test scores in the course of Smart Math Smart Life.

Comprehensive examination consists of midterm and final exams. A one-sample t-test is conducted to compare the test scores with the specified test levels as follows: midterm scores $(\mathrm{M}=8.89, \mathrm{SD}=3.87)$ are greater than the given score of 8.0, a statistically significant mean difference of $8.89,95 \%$ CI [ 8.03 to Inf], $t(56)=1.73, \mathrm{p}$ $=.045$. But there is not a significant difference in the final exam score compared with the specified score level at 8 points (One sample $t$-test; $t=-10.892, \mathrm{df}=56, \mathrm{p}<0.01$ ). However, the comprehensive test scores (midterm and final exam scores $(\mathrm{M}=12.76, \mathrm{SD}=6.27))$ are greater than the given score of 11.0, a statistically significant mean difference of $12.76,95 \% \mathrm{CI}$ [ 11.37 to Inf], $t(56)=2.12, \mathrm{p}$ $<0.001$. These results give that the proposed learning model makes the academic achievement of students higher than the specified score level at the level of 11 points. The correlations among scores of students who participated in the class are show in Table 3.

The interpretation from Table 3 is divided into 2 perspectives. The first point of view considers the mathematical achievement scores in developing subject-level learning outcomes, which include midterm and final exam scores, a Pearson's product-moment correlation was run to assess the relationship between scores in this course, there is significant evidence of a relationship between scores of mathematical achievement (Measure 6) and average score of O-NET (Measure 1) $(r=$ $0.56, \mathrm{p}<0.01)$, score of info graphic chart (Measure 3$)(r=$ $0.36, \mathrm{p}<0.01)$ and score of short video clip presentation (Measure 4) $(r=0.39, \mathrm{p}<0.01)$ and scores of online quiz (Measure 5) $(r=0.49, \mathrm{p}<0.01)$. Scores of mathematical achievement are not related to the score of problem solving in-class activity but it is moderately related to the others.

Another point of view is that there is also evidence of a relationship between the scores of in-class rainbow talk activity (Measure 4 ) and scores of online quiz (Measure 5) $(r=0.26, \mathrm{p}<0.05)$ which is weak but it is moderate related to scores of mathematical achievement.

Table 3. Pearson correlations among scores of students who participated in the class

\begin{tabular}{|c|c|c|c|c|c|c|}
\hline Measure & 1 & 2 & 3 & 4 & 5 & 6 \\
\hline $\begin{array}{l}\text { 1. Average score of O-NET for the subjects of } \\
\text { Mathematics }\end{array}$ & - & 0.13 & 0.07 & 0.20 & $0.40 * *$ & $0.56^{* *}$ \\
\hline 2. Score of problem solving in class activity & & - & $0.47 * *$ & -0.10 & $0.27 *$ & 0.14 \\
\hline $\begin{array}{l}\text { 3. Score of info graphic chart obtained in class } \\
\text { brainstorming session }\end{array}$ & & & - & 0.21 & $0.52 * *$ & $0.36^{* *}$ \\
\hline $\begin{array}{l}\text { 4. Score of short video clip presentation consists of } \\
\text { individual short video clip presentation form } \\
\text { brainstorming session and in-class rainbow talk } \\
\text { activity }\end{array}$ & & & & - & $0.26^{*}$ & $0.39^{* *}$ \\
\hline 5. Scores of online quiz after classroom activities & & & & & - & $0.49 * *$ \\
\hline $\begin{array}{l}\text { 6. Scores of mathematical achievement consist of } \\
\text { midterm and final examinations }\end{array}$ & & & & & & - \\
\hline
\end{tabular}

*, Correlation is significant at the 0.05 level (2tailed), $p<0.05$.

$* *$, Correlation is significant at the 0.01 level (2tailed), $p<0.01$. 


\subsection{Students Reflections}

Students gained experiences working with teammates and developed a presentation based on instructional learning in the rainbow talk activity. Students reported their experiences and gave positive comments as follows:

"This helps me to improve the explanation even more. Moderate fun! I can write the better chart."

"Gives us the courage to speak, dare to comment and dare to ask others about things that we don't know yet"

"Have fun!, I can share knowledge with friends. This activity makes us dare to speak, dare to present, and dare to make a video."

"Fun!, This activity gives us to be responsible."

"It makes us more responsible by automating and more diligent. Having fun during studying because we can ask our friends"

"From the rainbow talk activity, we can improve writing and give us to summarize all contents. Moreover, we can share some ideas to friends in the group as well"

"Some issues are hard to understand. But when coming to Rainbow. Talk at the end of the hour felt better understood"

"Rainbow talk activity is exciting because we have to understand it. So we will be able to summarize to friends (Sometimes we have to compete it with time)"

\section{Discussions and Conclusions}

This research has presented the blended learning that combines cooperative learning and flipped learning using rainbow talk activities, designed in accordance with the recommendations of research, called Preparation for Future Collaboration (PFC) [13].

The testing of the research assumptions reveals that students' academic performance is significantly improved with the blended learning and cooperative learning with flipped learning using rainbow talk activity. The rainbow talk activities encourage students to present their work and take their responsibilities to their work. The development of teamwork skills in cooperative learning encourages students to train discussions and provide mathematical reasons to solve the problem. The flipped learning takes the students to review their self-study lessons via the online classroom system. It also promotes the 21 st century technology skills. Other researches were successful in the application of flipped learning with cooperative learning, such as Munir, et al., [14] and Goedhart, et al., [15].

The cooperative learning using the rainbow talk activity in class must have enough time for students to learn. However, there are students who want more time to learn about activity hours. The reasonable duration and time limit in class activity is a crucial factor in the team learning of this model. Time factors also affect the students' responsibilities on the assignments that are assigned to the concept of gradual release of responsibility model, which reduces the importance if activity time in class is more than necessary.

Rainbow talk activity is a teaching learning which has the same idea as learning by doing. Learning by teaching encourages learning and sharing knowledge of students in class. These skills are part of the knowledge society, and this is also lifelong learning that is believed to be a way to keep people survive in the 21 st century [16]. Students can teach and learn from the others in rainbow talk activities, giving students both the role for teaching and studying. Both roles can improve the understanding of the more learning materials [17].

The open hour activity after the rainbow talk activity is an important part in the learning and teaching model proposed in this research. This activity is organized in class to provide feedback to students in overview. It also allows students to process their ideas in previous hours of activity. There is timely information, and some students may find out information that they need to apply in their activities.

The results of this study support the blended learning and cooperative learning with flipped learning activities using rainbow talk to enhance the academic achievement of students for improvement.

\section{REFERENCES}

[1] C. L. Lai, G.J. Hwang. A self-regulated flipped classroom approach to improving students' learning performance in a mathematics course, Computers \& Education, Vol.100, 126-140, 2016.

[2] C. K. Lo, K. F. Hew, G. Chen. Toward a set of design principles for mathematics flipped classrooms: A synthesis of research in mathematics education, Educational Research Review, Vol.22, 50-73, 2017.

[3] C. K. Lo, C. W. Lie, K. F. Hew. Applying "First Principles of Instruction" as a design theory of the flipped classroom: Findings from a collective study of four secondary school subjects, Computers \& Education, 118. 150-165, 2018.

[4] Y. Chen, Y. Wang, Kinshuk, N. S. Chen. Is FLIP enough? Or should we use the FLIPPED model instead?, Computers \& Education, Vol.79, 16-27, 2014.

[5] E. M. W. Ng. Integrating self-regulation principles with flipped classroom pedagogy for first year university students, Computers \& Education, Vol.126, 65-74, 2018.

[6] D. Fisher, N. Frey. Homework and the gradual release of responsibility: Making "responsibility" possible. English Journal, Vol.98, No.2, 40-45, 2008.

[7] N. C. Lin, H. F. Cheng. Effects of gradual release of responsibility model on language learning, Procedia Social and Behavioral Sciences Vol.2, 1868-1872, 2010.

[8] J. H. Shea, Problems with Collaborative Learning, Journal of Geological Education, Vol.43, No.4, 306-308, 1995.

[9] T. S. Roberts, J. M. McInnerney. Seven problems of online 
group learning and their solutions, Educational Technology \& Society, Vol.10, 257-268, 2007.

[10] S. Liu, M. Joy, N. Griffiths. Students' perceptions of the factors leading to unsuccessful group collaboration. Proceedings, 10th IEEE International Conference on Advanced Learning Technologies (ICALT2010), IEEE, $565-569,2010$.

[11] J. Grzega, M. Schöner. The didactic model LdL (Lernen durch Lehren) as a way of preparing students for communication in a knowledge society. Journal of Education for Teaching: International research and pedagogy, Vol.34, No.3, 167-175. 2008.

[12] I. P. B, Saligumba. D. A, Tan. Gradual Release Of Responsibility Instructional Model: Its Effects On Students' Mathematics Performance And Self-Efficacy, International Journal of Scientific \& Technology Research, Vol.7, No. 8, 276-291, 2018.
[13] R. Lam. What students do when encountering failure in collaborative tasks. npj Sci. Learn. 4, 6. 2019, Online available from https://doi.org/10.1038/s41539-019-0045-1.

[14] M. T. Munir, S. Baroutian, B.R. Young, S. Carter. Flipped classroom with cooperative learning as a cornerstone, Education for Chemical Engineers, Vol.23, 25-33, 2018.

[15] N. S. Goedhart, N. B. Westrhenen, C. Moser. The flipped classroom: supporting a diverse group of students in their learning. Learning Environment. Vol. 22, 297-310. 2019.

[16] D. Duran. Learning-by-teaching. Evidence and implications as a pedagogical mechanism, Innovations in Education and Teaching International, 2016.

[17] R. Roscoe. Self-monitoring and knowledge-building in learning-by-teaching. Instructional Science, Vol.42, 327$351,2014$. 